\title{
Effectiveness Of Structured Teaching Programme Vs. Self Instructional Module Regarding Prevention Of Acute Respiratory Infections In Children Among Mothers
}

\author{
K. Lakshmi Prasanna ${ }^{1}$; Naveen Kumar Sharma ${ }^{2}$ \\ ${ }^{1}$ Assistant professor, Indo American College of Nursing, Hyderabad \\ ${ }^{2}$ Tutor, College of Nursing, AIIMS, Jodhpur
}

\begin{abstract}
Acute respiratory infections are a major cause of mortality and morbidity in young children worldwide.ARIs are heterogeneous group of diseases with different causative factors and it affects different parts of respiratory tract. In this study two teaching strategies used to improve the knowledge of mothers regarding acute respiratory infections in under-five children.

The aim of the study was to determine the effectiveness of STP and SIM on knowledge regarding prevention of ARI among the two groups; and compare the effectiveness of STP and SIM on knowledge regarding prevention of ARI among the two groups.

The quasi experimental two group pretest post test design was adopted. Simple random technique was adopted to select 60 mothers .The data were generated structured interview schedule.STP \&SIM developed on ARI . Content validity of self constructed knowledge questionnaire, STP and SIM were obtained from experts of related departments. Mother's knowledge regarding ARI was assessed by using structured interview schedule method. On the first day of data collection (pre test) for STP \& SIM groups .STP was administered on the same day. On seventh day, again the same mother's knowledge was assessed (post-test) using the same tool. The reliability of tool was determined by using Spearman's Brown Prophecy formula. The reliability of the structured questionnaire was found to be 0.94 and validity of the tool found to be 0.973.The pilot was conducted on 10 mothers with constructed tool which it was found to be reliable.

The mean post test knowledge score 22.33 and $t$-value $(t(29)=16.018, P<0.01)$ of STP was apparently higher than SIM the mean post test knowledge score 19.77 and $t$-value $(t(29)=9.424, P<0.01)$ respectively. Hence STP is more effective than SIM. The developed tool can be used for different categories of population to evaluate the effectiveness of teaching strategies. Implication of various aspects of nursing are addressed and recommendations for future research are discussed.
\end{abstract}

Key Words: Structured teaching programme, Self instructional module and Acute Respiratory Infections

\section{Introduction}

Children are our future, numbering over 2.3 billion worldwide and representing boundless potential. Children are exposed to serious health risks from environmental hazards. Over $40 \%$ of the global burden of disease attributed to environmental factor falls on children below five years of age, who account for only about $10 \%$ world population, $60 \%$ of acute respiratory infections worldwide are related to environmental conditions ARI are a major cause of morbidity \& morality in your children worldwide. They account for nearly 4.1 million deaths every year globally. In an average a child has 5to 8 attacks of ARI annually. In India children below 14 years form $42 \%$ of the total population. ${ }^{1}$

Acute respiratory Infections are heterogeneous group of diseases with different causative factors and it affects different parts of respiratory tract .It can be classified according to the anatomic site of infection. Upper ARI includes common cold, pharyngitis, tonsillitis .Lower ARI includes bronchitis, bronchiolitis and pneumonia. ${ }^{2}$ while the magnitude of the problem of ARI \&its implications were not recognized until recently, major developing countries have now realized the need to focus attention on this problem .In our county too, ARIs constitute a serious health problem. They are responsible for $20-30 \%$ of deaths among under-five age \&mortality $40 \%$ in India. These figures are as a result of complex interplay of socio-economic status, climatic conditions, education, crowding, nutritional \&environmental factors \& more common in developing countries than developed countries. In the past few years there has been significant progress in our understanding of the problem of ARIs . Today many deaths can be prevented since supportive \&effective antibiotic therapy can be made available. ${ }^{3}$

Control of ARIs is a major public health problem in developing countries. Implementation of case management protocols requires participation of the community to reduce mortality \& morbidity from acute ARI .Health education programme can only be effective for prevailing knowledge, attitude \& practices of the community towards ARI in their children. ${ }^{4}$ 
Objectives of the present study is to assess the pretest \& posttest knowledge of regarding prevention of ARI among mothers; to determine the effectiveness of STP \&SIM on knowledge regarding prevention of ARI among the two groups; to compare the effectiveness of STP \&SIM on knowledge regarding prevention of ARI among the two groups; and to determine the association between knowledge on prevention of ARI \& selected variables.

Material and methods of study Pretest and post test design with experimental research approach used.

Setting of the study is Mahalakshmipuram urban area at Bangalore with population of Mothers of under five children

Sample and Sampling Technique 60 mothers of under five children was selected .Group I (STP) consists 30 mothers and group II (SIM) consists 30 mothers . Random sampling was used to select the houses of mothers of under five children. In each area researcher done the survey and selected 60 mothers by using simple random sampling technique.

The investigator used structured questionnaire to assess the knowledge of mothers regarding acute respiratory infections on children. Tool consists of two sections; Section -A Demographic data; Section -B Knowledge questionnaire .The knowledge level has been arbitrarily divided into three categories based on the mothers' scores. Adequate knowledge (Above 75\%) Score, Moderately adequate knowledge (51-75\%) Score, Inadequate knowledge (Below 50\%) Score

Result is organized, analyzed and presented in five sections, Section -I: Demographic data would be analyzed by using frequency and percentage; Section -II: The knowledge of the mothers would be analyzed in terms of frequency, percentage, mean, mean percentage and standard deviation; Section - III: Effectiveness of the STP and SIM; Section- IV: Compare the effectiveness of STP and SIM among the two groups; and Section- V: Association between demographic variables with knowledge score.

\section{SECTION- I}

TABLE - 1

Frequency and Percentage distribution of Respondents by Demographic Variables in STP group

\begin{tabular}{|c|c|c|c|}
\hline \multirow{2}{*}{ Demographic Variables } & \multirow{2}{*}{ Category } & \multicolumn{2}{|c|}{ Respondents } \\
\hline & & Number & Percent \\
\hline Age of the mother (Yrs) & $26-30$ & 16 & 53 \\
\hline Type of family & Nuclear & 21 & 70 \\
\hline \multirow{2}{*}{ Education } & Primary/Secondary & 18 & 60 \\
\hline & Graduate/Post-graduate & 12 & 40 \\
\hline \multirow{2}{*}{ Family income } & $1001-5000$ & 19 & 63 \\
\hline & $5001-10,000$ & 11 & 37 \\
\hline \multirow{2}{*}{ No. of children $0-5$ yrs } & 1 & 20 & 67 \\
\hline & 2 & 10 & 33 \\
\hline \multirow{2}{*}{ Source of information } & Health Personnel/Neighbors/Friends & 19 & 63 \\
\hline & Radio/TV & 11 & 37 \\
\hline \multirow{2}{*}{ No. of episodes of cold } & $\leq 3$ & 13 & 43 \\
\hline & $>3$ & 17 & 57 \\
\hline
\end{tabular}


TABLE - 2

Frequency and Percentage distribution of Respondents by Demographic Variables in SIM group

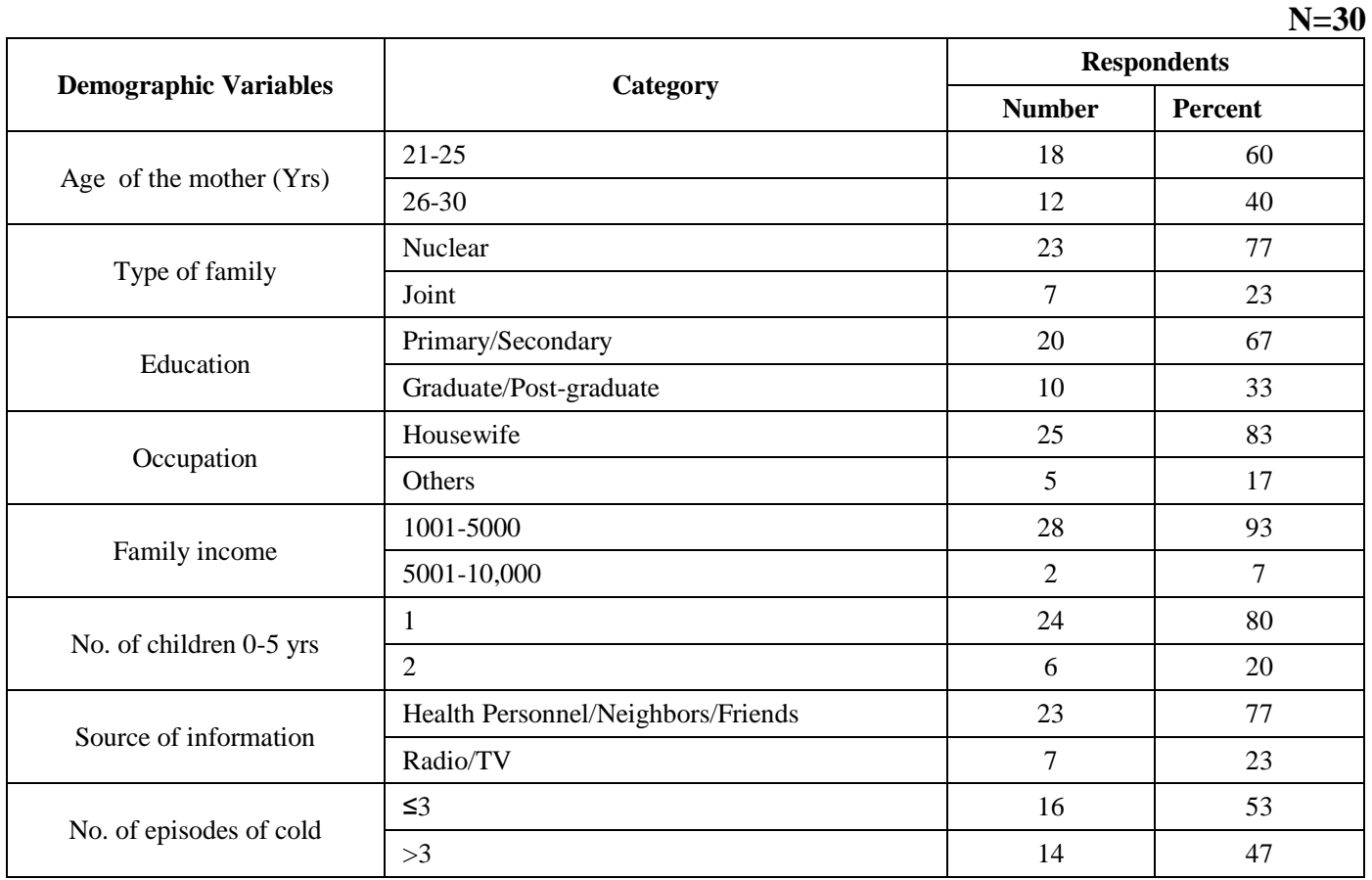

TABLE - 3

Pre test and Post test knowledge level of mothers on ARI in STP and SIM Group

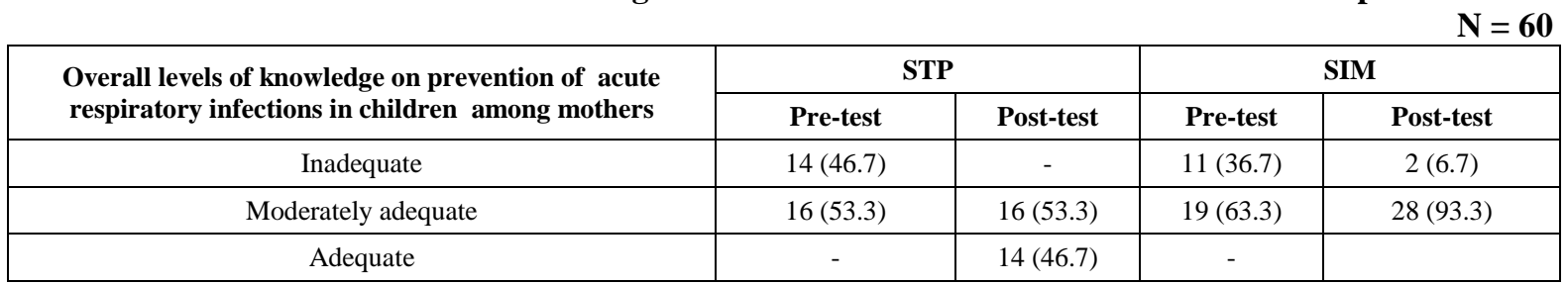

The data in this table shows that in STP group pretest knowledge scores of mothers on ARI 46.7\% had inadequate knowledge and $53.3 \%$ had moderately adequate knowledge. The post- test knowledge scores of mothers on ARI 53.3\% had moderately adequate knowledge and $46.7 \%$ had percent adequate knowledge. In SIM group pretest knowledge scores of mothers on ARI $36.7 \%$ had inadequate knowledge and $63.3 \%$ had moderately adequate knowledge. The post- test knowledge scores of mothers on ARI $6.7 \%$ had inadequate knowledge and $93.3 \%$ had moderately adequate knowledge.

Table $-\mathbf{4 . 1}$

Area wise pretest and post test knowledge level of mothers on ARI of STP group

\begin{tabular}{|c|l|c|c|c|c|c|c|}
\hline \multirow{2}{*}{ SI. No } & \multicolumn{1}{|c|}{ Aspects } & \multicolumn{3}{c|}{ Pretest } & \multicolumn{3}{c|}{ Post-test } \\
\cline { 2 - 9 } & \multicolumn{1}{|c|}{ STP group } & Mean & S.D & Mean\% & Mean & S.D & Mean\% \\
\hline 1. & $\begin{array}{l}\text { Definition, causes, } \\
\text { Clinical features }\end{array}$ & 2.40 & 0.86 & 48.00 & 3.57 & 1.17 & 71.33 \\
\hline 2 & Common Cold & 6.50 & 1.57 & 72.22 & 7.63 & 1.03 & 84.81 \\
\hline 3 & Bronchitis & 1.17 & 0.75 & 58.33 & 1.60 & 0.50 & 80.00 \\
\hline 4 & Pneumonia & 3.20 & 1.56 & 40.00 & 5.27 & 1.80 & 65.83 \\
\hline 5 & Preventive measures & 2.27 & 1.44 & 37.78 & 4.40 & 1.28 & 73.33 \\
\hline
\end{tabular}

From the above table it shows that mean percentage of pretest knowledge scores was highest (72.22\%) in the area of common cold and lowest $(37.78 \%)$ in the area of preventive measures. The mean percentage of post-test 
knowledge scores was highest $(84.81 \%)$ in the area of common cold and lowest $(65.83 \%)$ in the area of pneumonia.

Table -4.2

Area wise Pre test and Post test knowledge level of mothers on ARI of SIM group

\begin{tabular}{|c|l|c|c|c|c|c|c|}
\hline \multirow{2}{*}{ SI. No } & \multicolumn{1}{|c|}{ Aspects } & \multicolumn{3}{c|}{ Pretest } & \multicolumn{3}{c|}{ Post-test } \\
\cline { 2 - 9 } & \multicolumn{1}{|c|}{ SIM group } & Mean & S.D & Mean\% & Mean & S.D & Mean\% \\
\hline \multirow{2}{*}{1.} & $\begin{array}{l}\text { Definition, causes, } \\
\text { Clinical features }\end{array}$ & 3.00 & 0.69 & 60.00 & 3.10 & 0.71 & 62.00 \\
\hline 2 & Common Cold & 5.80 & 1.75 & 64.44 & 6.80 & 1.42 & 75.56 \\
\hline 3 & Bronchitis & 1.27 & 0.69 & 63.33 & 1.53 & 0.63 & 76.67 \\
\hline 4 & Pneumonia & 4.07 & 1.28 & 50.83 & 5.07 & 1.23 & 63.33 \\
\hline 5 & Preventive measures & 2.13 & 0.94 & 35.56 & 2.67 & 0.96 & 44.44 \\
\hline & Overall knowledge scores & 16.37 & 2.25 & 54.56 & 19.17 & 2.18 & 63.89 \\
\hline
\end{tabular}

From the above table it shows that mean percentage of pretest knowledge scores was highest (64.44\%) in the area of common cold and lowest $(35.56 \%)$ in the area of preventive measures. The mean percentage of post-test knowledge scores was highest $(76.67 \%)$ in the area of bronchitis and lowest $(44.44 \%)$ in the area of preventive measures.

TABLE -5

Comparison of Mean, Standard deviation of pre and post-test knowledge scores and t-value obtained by the mothers of STP Group and SIM Group

\begin{tabular}{|c|c|c|c|c|c|c|c|c|}
\hline Groups & \multicolumn{2}{|c|}{ Pre-test } & \multicolumn{2}{|c|}{ Post-test } & $\begin{array}{c}\text { Mean } \\
\text { difference }\end{array}$ & df & $\begin{array}{l}\text { Paired } \\
\text { t-value }\end{array}$ & Critical value \\
\hline SIM Group & 16.37 & 2.25 & 19.17 & 2.18 & 2.8 & 29 & $9.424^{\mathrm{NS}}$ & $<0.01$ \\
\hline
\end{tabular}

* Significant at 0.05 level; ** Significant at 0.01 level

From the above table it shows that for STP group mean post test knowledge score (22.33) is higher than the mean pretest knowledge score (15.53).The mean difference between pretest and post test score (6.8) of knowledge at 0.05 level as the $\mathrm{t}=16.08(* \mathrm{P}<0.01)$. For SIM group mean post test knowledge score $(19.17)$ is higher than the mean pretest knowledge score (16.37). The mean difference between pretest and post test score (2.8) of knowledge at 0.05 level as the $\mathrm{t}=9.424(* \mathrm{P}<0.01)$. From the above findings STP \& SIM group mothers have gained significantly in overall knowledge related to ARI. The differences are significant $\mathrm{p}<0.05$ from the values obtained from paired t-test at df: 29. It was also evident that mean difference gain in knowledge of STP Group is slightly more than gain in knowledge of SIM Group.

Table -6.1

Association between demographic variables and overall knowledge score of pre-test in STP group

\begin{tabular}{|c|c|c|c|c|c|c|c|}
\hline \multirow{2}{*}{$\begin{array}{l}\text { Demographic } \\
\text { variables }\end{array}$} & \multirow[t]{2}{*}{ Response } & \multicolumn{2}{|c|}{$\begin{array}{l}\text { Overall pre-test } \\
\text { knowledge of mothers of } \\
\text { STP group }\end{array}$} & \multirow{2}{*}{$\begin{array}{l}\text { Chi-square } \\
\text { value }\end{array}$} & \multirow[t]{2}{*}{ df } & \multirow{2}{*}{$\begin{array}{c}\mathrm{P}- \\
\text { value }\end{array}$} & \multirow[t]{2}{*}{ Inference } \\
\hline & & $\begin{array}{l}\text { Below } \\
\text { median }\end{array}$ & $\begin{array}{l}\text { Above } \\
\text { median }\end{array}$ & & & & \\
\hline \multirow{2}{*}{$\begin{array}{l}\text { Age of the mother } \\
\text { (Yrs) }\end{array}$} & $21-25$ & 11 & 3 & \multirow{2}{*}{3.772} & \multirow{2}{*}{1} & \multirow{2}{*}{0.052} & \multirow{2}{*}{ NS } \\
\hline & $26-30$ & 7 & 9 & & & & \\
\hline \multirow{2}{*}{ Type of family } & Nuclear & 15 & 6 & \multirow{2}{*}{\multicolumn{3}{|c|}{$\begin{array}{c}\text { Fisher's exact } \\
\text { probabilities }=0.062\end{array}$}} & \multirow{2}{*}{ NS } \\
\hline & Joint & 3 & 6 & & & & \\
\hline \multirow{2}{*}{ Education } & Primary/Secondary & 15 & 3 & \multirow{2}{*}{\multicolumn{3}{|c|}{$\begin{array}{c}\text { Fisher's exact } \\
\text { probabilities }=0.002\end{array}$}} & \multirow{2}{*}{$\mathrm{S}$} \\
\hline & Graduate/Post-graduate & 3 & 9 & & & & \\
\hline \multirow{2}{*}{ Family income } & $1001-5000$ & 14 & 5 & \multirow{2}{*}{\multicolumn{3}{|c|}{$\begin{array}{c}\text { Fisher's exact } \\
\text { probabilities }=0.051\end{array}$}} & \multirow{2}{*}{ NS } \\
\hline & $5001-10,000$ & 4 & 7 & & & & \\
\hline \multirow{2}{*}{ Occupation } & Housewife & 14 & 7 & \multirow{2}{*}{\multicolumn{3}{|c|}{$\begin{array}{c}\text { Fisher's exact } \\
\text { probabilities }=0.231\end{array}$}} & \multirow{2}{*}{ NS } \\
\hline & Others & 4 & 5 & & & & \\
\hline \multirow{2}{*}{$\begin{array}{l}\text { No. of children 0-5 } \\
\text { yrs }\end{array}$} & 1 & 10 & 10 & \multirow{2}{*}{\multicolumn{3}{|c|}{$\begin{array}{c}\text { Fisher's exact } \\
\text { probabilities }=0.117\end{array}$}} & \multirow{2}{*}{ NS } \\
\hline & 2 & 8 & 2 & & & & \\
\hline \multirow{2}{*}{$\begin{array}{l}\text { Source of } \\
\text { information }\end{array}$} & $\begin{array}{l}\text { Health } \\
\text { personnel/Neighbors/Friends }\end{array}$ & 11 & 8 & \multirow{2}{*}{\multicolumn{3}{|c|}{$\begin{array}{c}\text { Fisher's exact } \\
\text { probabilities }=0.534\end{array}$}} & \multirow{2}{*}{ NS } \\
\hline & Radio/TV & 7 & 4 & & & & \\
\hline
\end{tabular}




\begin{tabular}{|l|l|l|l|l|l|l|l|}
\multirow{2}{*}{$\begin{array}{l}\text { No. of episodes of } \\
\text { cold }\end{array}$} & $\leq 3$ & 9 & 4 & 0.814 & 1 & 0.367 & NS \\
\cline { 2 - 7 } & $>3$ & 9 & 8 &
\end{tabular}

From the above table it reveals that there is a significant association between knowledge score and the selected variable like education.

Table-6.2

Association between demographic variables and overall knowledge score of pre-test in SIM group

\begin{tabular}{|c|c|c|c|c|c|c|c|}
\hline \multirow{2}{*}{$\begin{array}{l}\text { Demographic } \\
\text { variables }\end{array}$} & \multirow{2}{*}{ Response } & \multicolumn{2}{|c|}{$\begin{array}{l}\text { Overall pre-test knowledge } \\
\text { of mothers of SIM group }\end{array}$} & \multirow{2}{*}{$\begin{array}{l}\text { Chi- } \\
\text { square } \\
\text { value }\end{array}$} & \multirow{2}{*}{ df } & \multirow{2}{*}{$\begin{array}{c}\mathrm{P}- \\
\text { value }\end{array}$} & \multirow{2}{*}{ Inference } \\
\hline & & $\begin{array}{c}\text { Below } \\
\text { median }\end{array}$ & $\begin{array}{l}\text { Above } \\
\text { median }\end{array}$ & & & & \\
\hline \multirow{2}{*}{$\begin{array}{l}\text { Age of the mother } \\
\text { (Yrs) }\end{array}$} & $21-25$ & 10 & 8 & \multirow{2}{*}{0.023} & \multirow{2}{*}{1} & \multirow{2}{*}{0.88} & \multirow{2}{*}{ NS } \\
\hline & $26-30$ & 7 & 5 & & & & \\
\hline \multirow{2}{*}{ Type of family } & Nuclear & 14 & 9 & \multirow{2}{*}{\multicolumn{3}{|c|}{$\begin{array}{c}\text { Fisher's exact } \\
\text { probabilities }=0.340\end{array}$}} & \multirow{2}{*}{ NS } \\
\hline & Joint & 3 & 4 & & & & \\
\hline \multirow{2}{*}{ Education } & Primary/Secondary & 13 & 7 & \multirow{2}{*}{\multicolumn{3}{|c|}{$\begin{array}{c}\text { Fisher's exact } \\
\text { probabilities }=0.181\end{array}$}} & \multirow{2}{*}{ NS } \\
\hline & Graduate/Post-graduate & 4 & 6 & & & & \\
\hline \multirow{2}{*}{ Occupation } & Housewife & 16 & 9 & \multirow{2}{*}{\multicolumn{3}{|c|}{$\begin{array}{c}\text { Fisher's exact } \\
\text { probabilities }=0.094\end{array}$}} & \multirow{2}{*}{ NS } \\
\hline & Others & 1 & 4 & & & & \\
\hline \multirow{2}{*}{ Family income } & $1001-5000$ & 16 & 12 & \multirow{2}{*}{\multicolumn{3}{|c|}{$\begin{array}{c}\text { Fisher's exact } \\
\text { probabilities }=0.687\end{array}$}} & \multirow{2}{*}{ NS } \\
\hline & $5001-10,000$ & 1 & 1 & & & & \\
\hline \multirow{2}{*}{$\begin{array}{c}\text { No. of children 0-5 } \\
\text { yrs }\end{array}$} & 1 & 14 & 10 & \multirow{2}{*}{\multicolumn{3}{|c|}{$\begin{array}{c}\text { Fisher's exact } \\
\text { probabilities }=0.531\end{array}$}} & \multirow{2}{*}{ NS } \\
\hline & 2 & 3 & 3 & & & & \\
\hline \multirow{2}{*}{$\begin{array}{l}\text { Source of } \\
\text { information }\end{array}$} & Health personnel/Neighbours/Friends & 11 & 12 & \multirow{2}{*}{\multicolumn{3}{|c|}{$\begin{array}{c}\text { Fisher's exact } \\
\text { probabilities }=0.089\end{array}$}} & \multirow{2}{*}{ NS } \\
\hline & Radio/TV & 6 & 1 & & & & \\
\hline \multirow{2}{*}{$\begin{array}{l}\text { No. of episodes of } \\
\text { cold }\end{array}$} & $\leq 3$ & 6 & 10 & \multirow{2}{*}{\multicolumn{3}{|c|}{$\begin{array}{c}\text { Fisher's exact } \\
\text { probabilities }=0.028\end{array}$}} & \multirow{2}{*}{$S$} \\
\hline & $>3$ & 11 & 3 & & & & \\
\hline
\end{tabular}

From the above table it reveals that there is a significant association between knowledge score and the selected variable like no. of episodes of cold.

\section{Discussion}

The present study shows that in STP group pretest knowledge scores of mothers on ARI $46.7 \%$ had inadequate knowledge and $53.3 \%$ had moderately adequate knowledge. The post- test knowledge scores of mothers on ARI 53.3\% had moderately adequate knowledge and $46.7 \%$ had percent adequate knowledge. In SIM group pretest knowledge scores of mothers on ARI $36.7 \%$ had inadequate knowledge and $63.3 \%$ had moderately adequate knowledge. The post- test knowledge scores of mothers on ARI $6.7 \%$ had inadequate knowledge and $93.3 \%$ had moderately adequate knowledge.

STP Group: The mean percentage of pretest knowledge scores was highest $(72.22 \%)$ in the area of common cold and lowest $(37.78 \%)$ in the area of preventive measures and remaining areas were definition, causes, clinical features (48\%), bronchitis $(58.33 \%)$ and pneumonia (40\%) respectively. The mean percentage of post-test knowledge scores was highest $(84.81 \%)$ in the area of common cold and lowest $(65.83 \%)$ in the area of pneumonia and remaining areas were definition, causes, clinical features $(71.33 \%)$, bronchitis $(80 \%)$ and pneumonia $(65.83 \%)$ respectively.

SIM Group: The mean percentage of pretest knowledge scores was highest $(64.44 \%)$ in the area of common cold and lowest $(35.56 \%)$ in the area of preventive measures and remaining areas were definition, causes, clinical features $(60 \%)$, bronchitis $(63.33 \%)$ and pneumonia $(50.83 \%)$ respectively. The mean percentage of post-test knowledge scores was highest $(76.67 \%)$ in the area of bronchitis and lowest $(44.44 \%)$ in the area of preventive measures and remaining areas were definition, causes, clinical features (62\%), bronchitis $(76.67 \%)$ and pneumonia $(63.33 \%)$ respectively.

In STP group the mean post test knowledge score is 22.33 was apparently higher than the mean pretest knowledge score is (15.53),suggesting STP was highly effective in increasing the knowledge scores of mothers on ARI . The mean difference between the post test and pretest knowledge score of mothers was found to be significant. $(\mathrm{t}(29)=16.018, \mathrm{P}<0.01)$

In SIM group the mean post test knowledge score is 19.77 was apparently higher than the mean pretest knowledge score is 16.37 , suggesting SIM was highly effective in increasing the knowledge scores of mothers 
on ARI. The mean difference between the post test and pretest knowledge score of mothers was found to be significant. $(\mathrm{t}(29)=9.424, \mathrm{P}<0.01)$

The mean post test knowledge score of STP group is 22.3 and $t$-value $(\mathrm{t}(29)=16.018, \mathrm{P}<0.01)$ was apparently higher than SIM group the mean post test knowledge score 19.77 and $t$-value $(\mathrm{t}(29)=9.424, \mathrm{P}<0.05)$ respectively .Hence STP is more effective than SIM. This confirms that structured teaching programme is an effective strategy compared to self instructional module .Hence hypothesis H1 was accepted.

The effectiveness of STP to improve knowledge had been supported in prior studies conducted by Ibrahim .M etal " a study to detect a difference in knowledge gain between students receiving structured versus student directed learning". The findings found that the traditional structured approach led to significantly greater knowledge gain in comparison with novel student -directed approach.$^{5}$

Another study was conducted to compare the two education strategies for teaching information criticism conducted in IMSS (Institute Mexicano del Seguro Social) Mexico. The results showed that the intervention for experimental group increased significantly $(\mathrm{p}<0.05)$ than control group and there is a need to promote educational participative strategies at all levels. ${ }^{6}$

There was a significant association between STP pretest knowledge scores of mothers and selected demographic variable like education but there was no significant association between pretest knowledge scores of mothers and selected demographic variable like age, type of family, occupation, family income, no. of children, source of information and no. of episodes of cold.

There was a significant association between SIM pretest knowledge scores of mothers and selected demographic variable like no. of episodes of cold but there was no significant association between pretest knowledge scores of mothers and selected demographic variable like age, education ,type of family, occupation ,family income ,no. of children and source of information .

\section{Conclusion}

The study findings revealed that majority of mothers had inadequate knowledge regarding ARI, and prevention of ARI; Different teaching strategies would help the mothers to updates with necessary knowledge with regards to the prevention of ARI; There was a significant association between the knowledge of subjects regarding ARI and selected demographic variables like education for STP and no. episodes of cold in children for SIM and there was no significant association between the knowledge of subjects regarding ARI and selected demographics variables like age, occupation, type of family, no. of children and source of information; There was a marked increase in post- test knowledge score than pre-test knowledge score for both STP \&SIM which explains the effectiveness of STP \& SIM. It is evident that the post mean percentage of STP is greater than post mean percentage of SIM. There was a high significant difference was found. Hence mothers should be encouraged to enhance their knowledge regarding prevention of ARI for proper care, support and timely management to prevent complication of child.

\section{NURSING IMPLICATIONS:}

\section{Community Health Nursing Practice:}

Mother is a key person for providing care to the children .So it was the primary responsibility of the PHN to assess the level of knowledge of mothers regarding ARI, both in specific learning and general areas. As a result health education strategies can be planned according to the needed area of knowledge regarding ARI, in both community set up and hospital settings.

\section{Nursing Education:}

Basic education of nursing and community health nursing professional include theory and practical aspect of education on ARI, especially emphasis on the area of causes, bronchitis, pneumonia ,prevention and management .Keen interest should be taken by the school health nurse, occupational health nurse and all public health professionals .Mothers should have up to date knowledge about ARI.

\section{Nursing Administration:}

A community health personnel plays a vital role to provide education to primary care providers like mothers to manage and prevent diseases like ARI which affect the future of the child. Education improves the awareness and skills to manage ARI in children for mothers. Being a nurse administrator should also takes initiative in organizing health education programme, supervision, special training programmes and periodic evaluation of programmes.

\section{Nursing research:}


Nursing research is crucial for the effective delivery of health care and for the role and status of the nursing profession. Different teaching strategies are effective in many ways; many more research studies are under taken in different fields in future for the effectiveness of different teaching strategies.

\section{References}

[1]. World health organization.Childrens environmental health. [Serial online] 2007 Jan [cited 2007 Aug 14]; Available from:URL:http://www.who.int

[2]. B.T Basavanthappa.Text book of community of health nursing.Jaypee brothers .second edition.

[3]. Padmaja kanchi,M.K. Kakery. Original research table .of contents Bombay hospital journal .A hospital based observational study of ARI. [Serial online] 2005 April [cited 2008 Aug 29]; Available from:URL:http://www.bhj.org/journal/htm

[4]. World health organization ARI control programme in India. [Serial online] 2000 [cited 2008 July 29]; Available from:URL:http://www.pub med.com

[5]. Ibrahim M, et al. Greater knowledge gain with structured than student-directed learning in child health. Med Teach 2006 May;28(3):239-43

[6]. Perez Rodriguez BA, Viniegra Velazquez L. the eduction of professors of medicine comparison of two education strategies for teaching information criticism. Rev Invest Clin 2003 May-Jun;55(3):281-8

[7]. Rashid S.F,Hadi A, Afsana K,Begu S.A.ARI in rural Bangladesh cultural understanding ,practices and role of the mother and community health volunteers.Trop med international health.2001 April ;6(4):24955

[8]. Nilanjan kumar mitra. Acute respiratory infections among rural under fives. Ind.Jr.com.med . [Serial online] 2001 Mar [cited 2007 Aug 14];26(1):25-7 Available from:URL:http://www.indian jr.com

[9]. Vijaya News paper. Awareness of mothers about the disease. Bangalore 2005 March 20

[10]. Acharya D, Prasanna KS, Nair S, Rao RS. ARI in children, Karnataka. Indian J Public health [serial online] 2003 Jan-Mar [cited 2008 Sep 28]; 47(1):713. Available from:URL:http://www.pubmed.com

[11]. Sharma AK. Magnitude of the problem of ARI. Indian Journal of communicable disease [serial online] 1998 [cited 2007 Aug 14]; 22-5. Available from:URL:http://www.journal commundis.org 